\title{
The time course of the immune response to experimental coronavirus infection of man
}

\author{
K. A. CALLOW ${ }^{1 *}$, H. F. PARRY ${ }^{2}$, M. SERGEANT ${ }^{1}$ AND D. A. J. TYRRELL ${ }^{1}$ \\ ${ }^{1}$ MRC Common Cold Unit, Harvard Hospital, Coombe Road, Salisbury, \\ Wiltshire SP2 8BW, UK \\ ${ }^{2}$ Department of Pathology, Salisbury Infirmary, Salisbury, Wiltshire, UK
}

(Accepted 10 May 1990)

\begin{abstract}
SCMMARY
After preliminary trials, the detailed changes in the concentration of specific circulating and local antibodies were followed in 15 volunteers inoculated with coronavirus $229 \mathrm{E}$. Ten of them, who had significantly lower concentrations of preexisting antibody than the rest, became infected and eight of these developed colds. A limited investigation of circulating lymphocyte populations showed some lymphocytopenia in infected volunteers. In this group, antibody concentrations started to increase 1 week after inoculation and reached a maximum about 1 week later. Thereafter antibody titres slowly declined. Although concentrations were still slightly raised 1 year later, this did not always prevent reinfection when volunteers were then challenged with the homologous virus. However, the period of virus shedding was shorter than before and none developed a cold. All of the uninfected group were infected on re-challenge although they also appeared to show some resistance to disease and in the extent of infection. These results are discussed with reference to natural infections with coronavirus and with other infections, such as rhinovirus infections.
\end{abstract}

\section{INTRODUCTION}

Relatively little work has been done recently on the immune response to respiratory virus infection. Early studies on the immediate response to rhinovirus, coxsackievirus, influenza and parainfluenza infections gave some indication of when local and circulating antibodies first appear and when the maximum titre occurs [1-5]. The change in the concentration of total IgA and protein in nasal secretions after infection was also followed $[2,3,6,7]$.

While some studies have shown that the concentration of local specific antibody declines relatively quickly after infection $[3,8]$ in others it has been shown to be more long-lasting [9]. Serum antibody is usually more persistent, possibly lasting for life $[8,10]$. More recently Barclay and colleagues [11] have shown that local and circulating rhinovirus antibodies are present at relatively high concentrations for at least 1 year after infection.

* Present address: 10A Donaldson Road, Salisbury, Wiltshire SP1 3DA. 
Both local and circulating antibodies have been shown to be associated with protection from infection and disease due to coronavirus [12]. While Macnaughton [13] showed that circulating antibody may last no longer than 5 months, Reed [14] indicated that, in volunteers, immunity could last at least a year. However no more detailed studies on the immune response to coronavirus infection have been undertaken, particularly on the kinetics of antibody production after infection. In this study, volunteers at the Common Cold Unit were used to study short-term changes in specific antibody concentrations after infection with coronavirus $229 \mathrm{E}$. This was in order to answer such questions as how soon local and circulating antibody concentrations start to increase and when the peak concentration is reached. Total blood lymphocytes and their subsets were also examined because it has been shown that lymphocytopenia, particularly of T-cells, occurs in the early stages of rhinovirus [15] and influenza infections [16-18]. Thereafter the long-term changes in antibody concentration were followed and resistance to intranasal virus challenge was estimated 1 year after first exposure. Finally. in order to compare these results with the longevity of immunity in natural coronavirus infections, sequential sera taken from subjects taking part in a field study of influenza prophylaxis [19] were examined. Some of these subjects had apparently been naturally infected with coronavirus $229 \mathrm{E}$ and others with the other major human coronavirus serotype, OC43.

\section{METHODS}

\section{Volunteers}

The isolation, inoculation and assessment of volunteers have been described elsewhere [20, 21]. In preliminary experiments, 16 volunteers stayed for a standard trial. After a 3-day quarantine period they were inoculated intranasally with $100 \mathrm{TCID}_{50}$ of coronavirus $229 \mathrm{E}$ contained in a filtered pool of nasal washings. They left the unit after a further 6 days but provided blood samples by post 2 and 11 weeks later. In addition, six volunteers returned for unrelated trials after about 1 year and thus provided further samples.

Extended trials were then organized in which volunteers stayed for 3 weeks after virus inoculation and frequent nasal washing and blood samples were taken. In addition, a blood sample was sent to the unit 8 weeks after inoculation and volunteers attended the unit at 11 weeks for further nasal washing and blood samples to be taken. At about 52 weeks, volunteers returned for a standard challenge trial in which coronavirus $229 \mathrm{E}$ was again inoculated. All these trials were approved by the Harrow District Ethical committee.

\section{Nasal washings}

Collection and treatment of nasal washings have been described elsewhere [22]. Briefly, $10 \mathrm{ml}$ of phosphate buffered saline (PBS) were instilled into the nostrils in several aliquots and forcibly expelled. For antibody and protein measurement, washings were vortexed with glass beads, clarified by centrifugation, and stored at $-20^{\circ} \mathrm{C}$. Nasal washings for virus isolation were mixed with nutrient broth and stored at $-70^{\circ} \mathrm{C}$. Virus was detected by inoculation of roller tube cultures of the C-16 line of MRC-C cells [23]. 


\section{Blood samples for enumeration of lymphocyte sub-sets}

These were taken before, and 4 and 10 days after, virus inoculation. White cells were separated by standard methods, using lymphocyte separation medium (Flow Laboratories) and smears were prepared in a Cytospin 2 (Shandon). T-cells, B-cells and helper/suppressor cells were labelled by immuno-alkaline phosphatase staining as described previously [24]. Total lymphocytes were counted by standard methods.

Blood samples for serum were separated and sera were stored at $-20^{\circ} \mathrm{C}$.

Neutralizing antibody titres were measured by a micro-neutralization test [21] in $\mathrm{C}-16$ cells.

\section{Protein assays}

These were performed by a modification of the method of Lowry and colleagues [25] where, in the final step, samples were removed to ELISA plates and the optical densities (OD) read at $700 \mathrm{~nm}$ in a Dynatech MR700 ELISA reader.

\section{Assay of specific IgA in nasal washings by ELISA}

ELISA plates (Nunc Immunoplates U type II) were coated with coronavirus $229 \mathrm{E}$ or control antigen as described previously [12]. After washing three times with PBS containing $0.05 \%$ Tween 20 (TPBS), the plates were blocked with $0.5 \%$ bovine serum albumen (BSA) for $1 \mathrm{~h}$ at $37^{\circ} \mathrm{C}$. After washing the plates nasal washings, diluted $1: 10$ in TPBS containing 10\% control antigen and $0.1 \% \mathrm{BSA}$, were added and incubated for $5 \mathrm{~h}$ at $4{ }^{\circ} \mathrm{C}$. Goat anti-human $\operatorname{IgA}(\alpha$ chain) conjugated to alkaline phosphatase (Sigma Chemical Co.), diluted 1:1000, was added and incubated at $4{ }^{\circ} \mathrm{C}$ overnight. The substrate, p-nitrophenol phosphate, was added as described previously [12]. A standard pool of nasal washings given an arbitrary concentration in units was titrated on each assay plate [22].

\section{Assay of specific antibodies in sera}

Sera were diluted 1:80 for specific IgA and 1:240 for IgG assay, using the same diluent as for nasal washings. Plates were coated and blocked as before except that, for specific IgG measurement, control antigen-coated wells were not used as these always gave very low readings. Sera were incubated for $2 \mathrm{~h}$ at $37^{\circ} \mathrm{C}$. AntiIgA conjugate, or anti-IgG conjugate (Miles Laboratories), diluted 1:1000 was added and incubated for $2 \mathrm{~h}$ at $37^{\circ} \mathrm{C}$ and substrate was added as before. A pool of standard serum, given an arbitrary concentration in units, was titrated on each plate, except in some experiments where results are quoted as OD.

\section{Reading the plates and calculation of results}

Plates were read on a Titertek Multiskan ELISA reader (Flow Laboratories) at $405 \mathrm{~nm}$. For specific IgG assays, plates were read at 20 and $30 \mathrm{~min}$, and for specific IgA at 60 and $75 \mathrm{~min}$. The ELISA reader was linked to a Sirius 1 microcomputer, which ran a program for collection of data, calibration of standards and calculation of the results. All the following calculations were performed by the program which was written by Clive Thomas of the Clinical Research Centre, Harrow, Middlesex. Except in the case of the specific IgG assay, the OD in control 
antigen-coated wells were subtracted from those in the virus-coated wells. All samples and standards were run in duplicate and means were calculated. The concentration in units of the samples was calculated from the calibration curve of the standards. The final concentration of antibody was calculated from the mean of readings taken at two different times.

Specific $\operatorname{IgA}$ in nasal washings was standardized against protein concentration [1]. Concentrations of protein in any one individual remain fairly constant from day to day [4; Callow, unpublished observations].

The method used to establish a significant rise in serum specific IgG has been described previously $[12,22]$. Paired sera from 14 volunteers who received intranasal saline instead of virus were tested for specific $\operatorname{IgG}$ as described above. A significant rise was set as the mean difference between these paired sera plus two standard deviations, i.e. $0 \cdot 14 \log _{10}$ units in this study.

\section{Statistical methods}

The analysis was performed on an IBMX'T computer using the program, Statistical Package for Personal Computers (SPP) written by Patrick Royston of the Clinical Research Centre. To examine the difference in antibody concentration on different days, in particular on any day compared with the pre-challenge value, and to compare antibody concentrations in infected and uninfected volunteers, $t$ tests were used.

\section{Treatment of missing values}

There were a few instances when samples were not available for investigation. In these cases, for the graphical representation of results, an estimate of the value of single missing samples was obtained by interpolation from the value of the samples taken just before and after the missing ones. This estimate was not used for statistical analysis.

\section{Field study}

Serological response to natural coronavirus infection was investigated by testing sera obtained in a field study of influenza prophylaxis described elsewhere [19]. Briefly, this involved military personnel volunteers who were given either influenza vaccine, amantadine (during influenza epidemics) or placebo prophylactically. Respiratory tract illnesses were recorded over a 3-year period, and infections with common respiratory viruses diagnosed by isolation from nose or throat swabs, and/or by seroconversion. Serum samples were obtained at the beginning of the study, at 4-6 week intervals thereafter, and in the acute and convalescent stages of any respiratory illness.

\section{RESLLTS \\ Preliminary trials}

Neutralizing antibodies and specific IgG and $\operatorname{IgA}$ in sera were monitored during and after infection with coronavirus $229 \mathrm{E}$ in 16 volunteers on standard 10-day trials. Although concentrations of all three types of antibody were significantly raised in sera taken about 3 weeks after inoculation, by 12 weeks the concentrations had fallen considerably. Fig. 1 shows these effects in six volunteers 

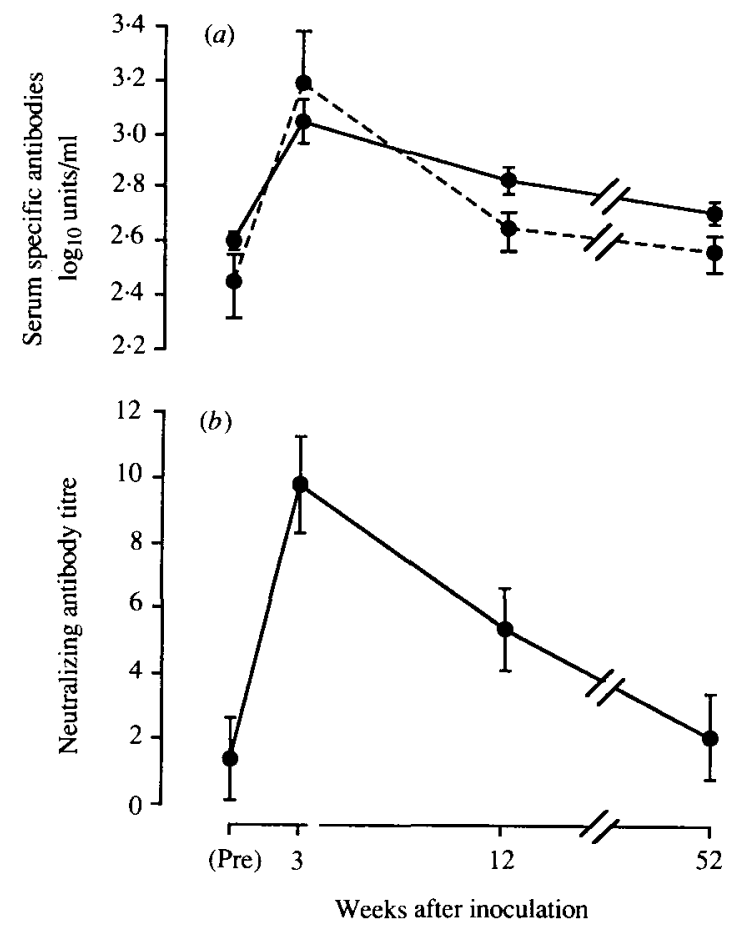

Fig. 1. Changes in concentration of serum antibodies (geometric mean) of six volunteers infected with coronavirus $229 \mathrm{E}$ in preliminary trials. Bars represent the standard error of the mean. (a) Specific IgG antibody titres.

from whom serum samples were also available 1 year later. By this time mean antibody concentrations were only slightly higher than those measured before the trial. There were considerable individual differences however. Two volunteers had retained high concentrations of specific $\operatorname{IgG}$, the others had returned to their baseline values or just above.

With this preliminary information extended trials were planned to obtain details of changes in both serum and nasal antibody in the first 3 weeks after virus inoculation as well as long-term changes.

\section{Extended trials}

(a) Infection and illness resulting from coronavirus inoculation

Of 15 volunteers inoculated with coronavirus, 10 became infected as indicated by virus shedding on at least 1 day. All of these also had a significant rise in serum specific IgG. Eight of the 10 infected volunteers had clinical colds of varying severity. For the purposes of this study the volunteers were divided into two groups, an infected and an uninfected group.

\section{(b) Changes in total blood lymphocytes}

The mean total lymphocyte count before challenge was higher in the infected group than the uninfected group, although this difference was not statistically significant (Table 1). In the infected group there was a significant decrease in 
Table 1. Mean concentration $\left(\times 10^{-9} / l\right)$ of total blood lymphocytes in volunteers inoculated with coronavirus $229 \mathrm{E}$

\begin{tabular}{lccc} 
& \multicolumn{3}{c}{ Days after challenge } \\
\cline { 2 - 4 } Pre & 4 & 10 \\
Infected volunteers & $2 \cdot 41$ & $2 \cdot 13^{*}$ & $2 \cdot 55^{*}$ \\
Cninfected & $2 \cdot 02$ & $2 \cdot 10$ & $2 \cdot 17$ \\
* Significantly different $(P<0.05)$ from previous value.
\end{tabular}

counts 4 days after virus inoculation $(P<0 \cdot 05)$, 8 out of the 10 showing lymphocytopenia of up to $25 \%$. There was a significant increase again 1 week later. There appeared to be no relationship between these changes and the severity of symptoms. No other parameters, i.e. $\% \mathrm{~T}$ or $\mathrm{B}$ cells or helper/suppressor ratios were significantly changed in either group (data not shown).

\section{(c) Changes in nasal-washing IgA}

Mean concentrations of specific $\operatorname{IgA}$, standardized relative to protein concentrations, in the two groups are shown in Fig. $2 a$. Similar curves were obtained if concentrations were not standardized, or standardized relative to total IgA concentrations. The infected volunteers entered the trials with a significantly lower concentration of nasal antibody, 74 units $/ \mathrm{mg}$ protein compared with the uninfected volunteers, 398 units $/ \mathrm{mg}(P<0.05)$. The day after inoculation there was an immediate increase in the amounts of antibody in both groups compared with those existing before the trial. In the case of the uninfected volunteers this increase was significant at $P<0.05$. After some fluctuations in this group, the concentrations slowly declined and by 11 weeks they were slightly below those existing at the start of the trial. In contrast the infected group showed an initial decrease of antibody concentration, in some subjects becoming undetectable. This was followed by a sharp increase starting about 1 week after challenge, which coincided with the end of virus shedding in some subjects, while in others it occurred after virus shedding stopped (see legend to Fig. 2). After reaching a maximum about 10 days later the concentration slowly declined, and although from 12 days to 11 weeks after inoculation concentrations were significantly higher than before the trial, by 11 weeks the mean concentration was less than in the uninfected group.

No significant changes in coronavirus specific $\operatorname{IgA}$ concentrations were seen in nasal-washings of four volunteers inoculated with saline or of five inoculated with rhinovirus (data not shown).

(d) Changes in serum specific IgA

The uninfected group had more serum specific IgA (120 units/ml) before inoculation than the infected group $(38$ units $/ \mathrm{ml})(P<0 \cdot 05$, Fig. 2b). Although there were minor fluctuations, the concentrations remained fairly constant in the former group throughout. In contrast the infected group showed a sharp increase about 8 days after inoculation. From 10-20 days after inoculation concentrations were significantly higher than before but after a peak at 14 days, specific IgA declined and by 8 weeks was slightly less than in the uninfected group. There were 

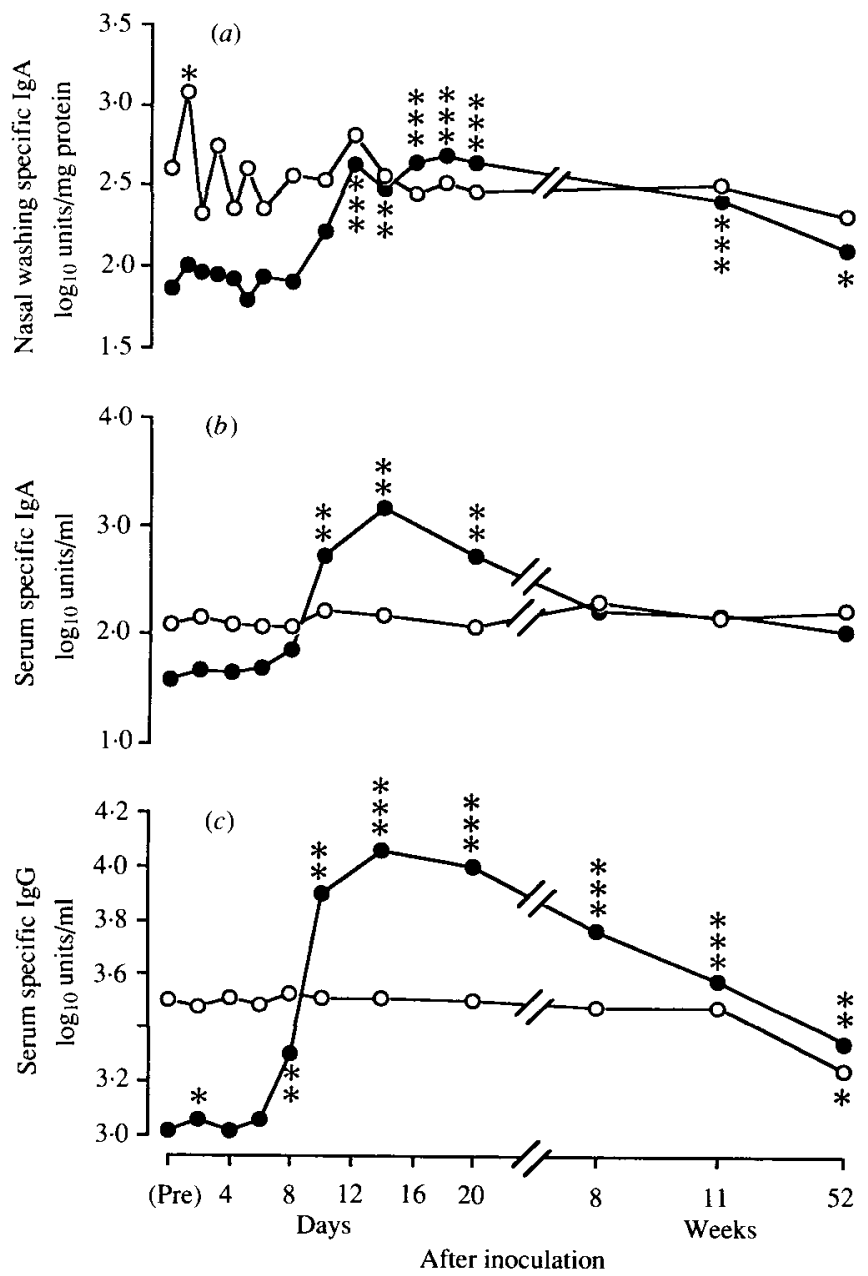

Fig. 2. Changes in specific antibodies up to 1 year after coronavirus $229 \mathrm{E}$ inoculation. Geometric mean concentration in uninfected (O) and infected (O) volunteers. Significance of difference from pre-inoculation values: $* * * P<0.001, * * P<0.01$, $* P<0.05$. All these significant differences represent increases except for IgG 1 year after inoculation in uninfected volunteers where there was a significant decrease. $(a) \operatorname{IgA}$ in nasal washings. (The percentage of infected volunteers shedding virus was: 1 day after inoculation, $10 \% ; 2$ days, $80 \% ; 3$ days, $90 \% ; 4-6$ days, $100 \% ; 8$ days, $50 \% ; 10$ days, $20 \% ; 12$ days, $0 \%$. (b) IgA in sera. (c) IgG in sera.

considerable individual differences in both groups. For example, two uninfected volunteers maintained high concentrations throughout the period, while two infected volunteers showed no significant rise in serum specific IgA. In 4 of the remaining 8 infected volunteers, concentrations had returned to pre-inoculation values by 8 or 11 weeks.

(e) Changes in serum specific $I g G$

The uninfected group had more specific IgG in pre-inoculation sera (3162 units $/ \mathrm{ml})$ than the infected group (1047 units $/ \mathrm{ml})(P=0.05)$, and in the former group the mean concentration remained remarkably constant throughout the trial 
(Fig. 2c). The infected group had an immediate slight increase $(P<0.05)$ in antibody titres followed by a decrease. A sustained rise began about 8 days after inoculation, reaching a peak at 14 days. Thereafter there was a slow decline, and although between 8 days and 11 weeks after inoculation concentrations were significantly higher than at the start of the trial, at 8 and 11 weeks they were not significantly higher than in the uninfected group.

\section{(f) Antibody concentration 1 year after challenge}

All of the volunteers, except for one infected individual were able to return to the unit approximately 1 year later.

Between 11 weeks and 1 year after challenge, nasal washing specific IgA appeared to decline in both groups (Fig. 2a). However the uninfected group showed no significant difference from before the trial, and, while in the infected group concentrations were still significantly raised $(P<0.05)$ compared with before the trial, they were now lower than in the uninfected group. Serum specific IgA showed no significant changes (Fig. 2b). In the infected group the mean concentration was still slightly raised compared with before the trial, but concentrations had become slightly lower than in the uninfected group.

Serum specific IgG declined in both groups (Fig. 2c). However, while concentrations in the uninfected group were significantly lower than before the trial $(P<0.05)$, in the infected group concentrations were still significantly higher than before the trial $(P=0 \cdot 01)$. However in one infected volunteer the concentration of this antibody was lower than before the trial, and in another had almost returned to its original value.

\section{(g) Results of re-challenge}

Volunteers were re-challenged with the same dose of coronavirus. Of the original uninfected group of five, all became infected as judged by virus shedding on at least one day and/or a significant rise in serum specific IgG and one had a cold. Of the original infected group, 6 out of 9 became reinfected, using the same criteria, but none developed a cold.

One distinguishing feature of the two sets of trials was that virus shedding was of a much shorter duration, in both groups, on re-challenge. In those that shed virus at all, the mean duration was $5 \cdot 6$ days in the first trial, and $2 \cdot 0$ days in the second.

\section{Field study - changes in serum specific IgG in natural infections}

Serial serum samples had been taken over 2 years from 11 subjects in a field study of respiratory disease in servicemen in Canada. Infections with either coronavirus $229 \mathrm{E}$ or OC43 were detected by rises in serum specific IgG against one or the other serotype. Three subjects showed a decrease in antibody to $229 \mathrm{E}$, as measured by OD in the ELISA test, similar to that seen in volunteer trials (Fig. $3 a$ ). Eight subjects infected with OC43 were also followed up. Despite individual variations, all showed a distinct decline in antibody after convalescence (Fig. $3 b$, c). In two subjects from whom later samples were available, antibody returned to pre-infection values by 33 and 50 weeks respectively (Fig. $3 c$ ). 

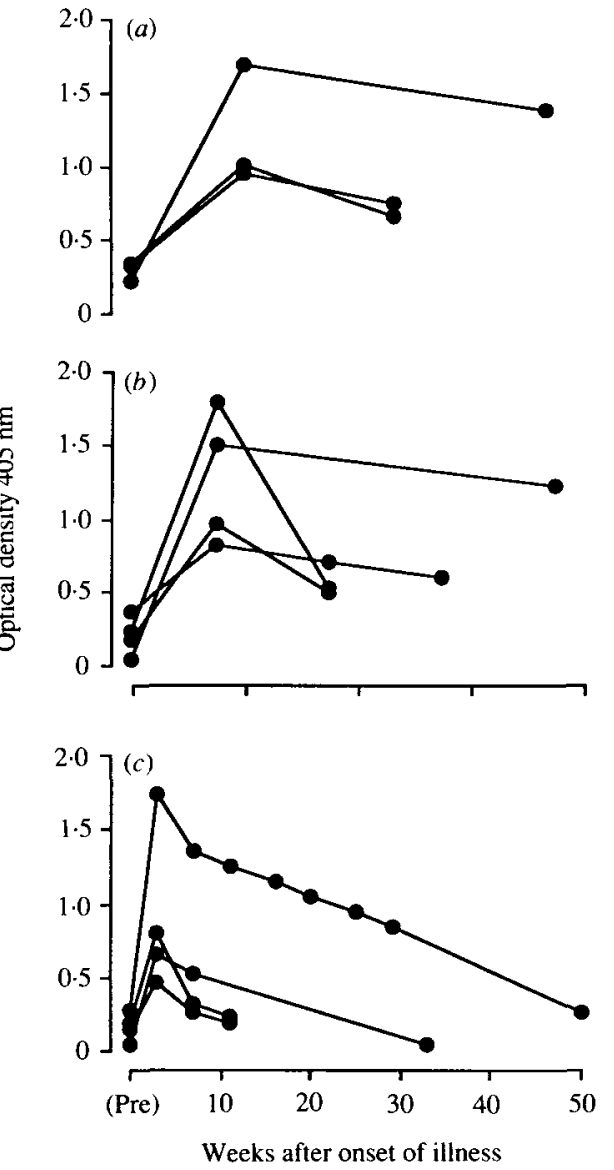

Fig. 3. Changes in concentration of serum specific IgG in individual subjects naturally infected with coronavirus, as measured by ELISA optical density. (a) Infected with the serotype $229 \mathrm{E}$. $(b, c)$ Infected with the serotype OC43.

\section{DISCUSSION}

This extended trial represents the most detailed study yet reported of immune responses to human coronavirus infections. It shows that the immunological changes during and after coronavirus infection, are in some respects like those which follow other respiratory infections such as rhinovirus infections, while in other respects they are different.

As in infections with rhinovirus [15] and influenza [16-18], lymphocytopenia occurred in the early stages of infection. It is thought that this reduction may reflect migration of lymphocytes to the nasopharyngeal site of infection [15, 17]. However in contrast to these other studies the reduction was transient and slight; a mean decrease of $11.6 \%$ compared with $28 \%$ in rhinovirus infection [15]. Furthermore there was no relationship between the amount of decrease and symptom scores, and no significant changes in the proportions of T-cells, B-cells or $\mathrm{T}$-cell subsets, as was shown in other infections. If we had been able to take 
more frequent samples we might have detected a greater decrease on another day, together with changes in T- or B-cells. Further work should determine whether this is the case.

The initial sharp, transient increase in local antibody in the uninfected group has been observed previously in coronavirus infections (Callow, unpublished observations). One can discern a similar, but slightly later, peak in the relevant figure in the study of Barclay and colleagues [11] of rhinovirus infections. Butler and co-workers [2] recorded an increase in total $\operatorname{IgA}$ in nasal secretions $24 \mathrm{~h}$ after rhinovirus inoculation. Until now, sufficiently sensitive methods for recording such changes in specific antibody have not been available. The increase may represent an anamnestic response resulting from previous infections, being a specific discharge from loaded cells, or it may have resulted from an as yet unrecognized mechanism. The later steep rise in concentration of nasal antibody in the infected group coincided with, and may have been the reason for, the cessation of virus shedding.

Maximum concentrations of both circulating and local antibody occurred at 12-14 days. In rhinovirus infections [11] the rise and particularly the maximum (35 days) are later. After this maximum there was quite a steep decline, whereas in rhinovirus infection there is no decline. Barclay and colleagues [11] suggest that this may be due to repeated stimulation by related cold viruses. Since there are only two sub-types of coronaviruses, such stimulation would be less likely to occur.

Although after 1 year concentrations of specific serum $\operatorname{IgG}$ and nasal $\operatorname{Ig} A$ were still significantly raised in the infected group, they were much lower than at the maximum. This latter observation confirmed that seen in preliminary trials.

When challenged after 1 year all of the original uninfected group were infected and 6/9 of the infected group were reinfected. These data do not fit any simple model. It may be that the small amounts of antibody remaining in the original infected group contributed to resistance to reinfection in some volunteers. It may also have prevented colds and shortened the duration of virus shedding. The original uninfected group also shed virus for only a short time and only one volunteer got a cold. Their mean antibody concentrations were still higher than in the infected group before the first trial. They could have had an intervening coronavirus infection or perhaps tend to have higher concentrations of specific antibody at any time. This could be because they produce more antibody as a result of infection or, as appears more likely from this study, they retain antibody for longer. Further study of peak concentrations and rates of decline is necessary to ascertain which is the case. In the infected group there were considerable individual differences. Some lost their antibody, particularly serum antibody, completely by 1 year, some did not. Such differences are also seen in rhinovirus infections [11]. They indicate that resistance may be a more inherent characteristic than is generally supposed. It is known that extroversion, obsessionality and other essentially permanent psychological characteristics seem to be related to infection rates [26, 27]. We are now studying links between such characteristics and antibody concentrations. Other factors must be analysed as well; for example, the cellular arm of the immune system may play a role.

The incidence of reinfection after 1 year was greater than that observed with 
rhinovirus infection [11] and did not support Reed's study [14] in which reinfection with a homologous coronavirus strain after 1 year did not occur. Also, antibody was still declining, albeit slowly. Coronaviruses have been shown to cause almost $20 \%$ of all colds [28] and since the two main serotypes are roughly equally prevalent (Callow, unpublished observation), any one serotype would cause about $10 \%$ of all colds. Since adults have about two colds per year on average $[29,30]$ and about half of all coronavirus infections are subclinical [31, 32], each adult should have a coronavirus infection every $2-3$ years. This agrees with Monto [33] who suggested a 2-3 year cyclic pattern. It indicates that protective amounts of antibody may have disappeared by 2 years, and that if we had been able to reinoculate the volunteers after a further year, the reinfection rate would have been even higher.

In the few natural infections studied a marked decline in antibody was also observed, but a strict comparison with the size and speed of decline in volunteers is impossible because the results were obtained using OD rather than antibody concentrations. Furthermore, data for an extended period were only obtained for the strain OC43 and only on a few individuals. Again large individual differences were observed.

The observed differences from rhinovirus infection may simply reflect differences in the number of serotypes. However they may also be due to differences in the structure of the viral epitopes and the frequency and nature of their interaction with the immune system.

\section{ACKNOWLEDGEMENTS}

We wish to thank the volunteers for their particularly loyal co-operation, Dr G. I. Barrow, Mrs A. Dalton and Miss J. Dunning for the clinical observations, and Miss M. Forsyth, Miss C. Dearden and Mr S. Carey for technical assistance.

\section{REFERENCES}

1. Cate TR, Rossen RD, Gordon Douglas R Jr, Butler WT, Couch RB. The role of nasal secretion and serum antibody in the rhinovirus common cold. Am J Epidemiol 1966; 84: $352-63$.

2. Butler WT, Waldmann TA, Rossen RD, Gordon Douglas R Jr, Couch RB. Changes in IgA and IgG concentrations in nasal secretions prior to the appearance of antibody during viral respiratory infection in man. J Immunol 1970; 105 : $584-91$.

3. Alford RH, Rossen RD, Butler WT, Kasel JA. Neutralizing and hemagglutinationinhibiting activity of nasal secretions following experimental human infection with A2 influenza virus. J Immunol 1967; 98 : 4724-31.

4. Rossen RD, Butler WT, Waldmann RH, et al. The proteins in nasal secretion. II A longitudinal study of $\operatorname{IgA}$ and neutralizing antibody levels in nasal washings from men infected with influenza virus. JAMA $1970 ; 211: 1157-61$.

5. Yanagihara R, McIntosh K. Secretory immunological response in infants and children to parainfluenza virus types 1 and 2 . Infect Immun $1980 ; 30: 23-8$.

6. Rossen RD, Butler WT, Cate TR, Szwed CF, Couch RB. Protein composition of nasal secretion during respiratory virus infection. Proc Soc Exp Biol Med 1965; 119; 1169-76.

7. Crifo S, Vella S, Filiaci F, Resta S, Rocchi G. Secretory immune response after nasal vaccination with live attenuated influenza virus. Rhinology 1980;18: 87-92.

8. Holmes MJ, Reed SE, Stott EJ, Tyrrell DAJ. Studies of experimental rhinovirus type 2 infections in polar isolation and in England. J Hyg 1976; 76; 379-93. 
9. Buscho RF, Perkins JC, Knopf HLS, Kapikian AZ, Chanock RM. Further characterisation of the local respiratory tract antibody response induced by intranasal instillation of inactivated rhinovirus 13 vaccine. J Immunol 1972; 108: 169-76.

10. Taylor-Robinson D. Studies on some viruses (rhinoviruses) isolated from common colds. Arch ges Virusforsch 1963; 13: 281-93.

11. Barclay WS, Al-Nakib W, Higgins PG, Tyrrell DAJ. The time course of the humoral immune response to rhinovirus infection. Epidemiol Infect $1990 ; 103: 659-69$.

12. Callow KA. Effect of specific humoral immunity and some non-specific factors on resistance of volunteers to respiratory coronavirus infection. J Hyg 1985; 95 : 173-89.

13. Macnaughton MR. Occurrence and frequency of coronavirus infections in humans as determined by enzyme-linked immunosorbent assay. Infect Immun 1982; 38 : 419-23.

14. Reed SE. The behaviour of recent isolates of human respiratory coronavirus in vitro and in volunteers. J Med Virol 1984; 13: 179-93.

15. Levandowski RA, Ou DW, Jackson GG. Acute-phase decrease of T lymphocyte subsets in rhinovirus infection. J Infect Dis $1986 ; 153: 743-8$.

16. Scheinberg MA, Blacklow NR, Goldstein AL, Parrino TA, Rose FB, Cathcart ES. Influenza: response of T-cell lymphopenia to thymosin. New Engl J Med 1976; 294 : $1208-11$.

17. Dolin R, Richman DD, Murphy BR, Fauci AS. Cell-mediated immune responses in humans after induced infection with influenza A virus. J Infect Dis 1977 ; 135 : 714-9.

18. Faguet GB. The effect of killed influenza virus vaccine on the kinetics of normal human lymphocytes. J Infect Dis $1981 ; 143: 252-8$.

19. Aoki FY, Stiver HG, Sitar DS, et al. Potential of influenza vaccine and amantadine to prevent influenza A illness in Canadian Forces Personnel 1980-1983. Milit Med 1986; 151 : $459-65$.

20. Beare AS, Reed SE. The study of antiviral compounds in volunteers. In: Oxford JS, ed. Chemoprophylaxis and virus infections of the respiratory tract vol II. Cleveland: CRC Press, $1977 ; 27-55$.

21. Higgins PG, Phillpotts RJ, Scott GM, Wallace J, Bernhardt LI, Tyrrell DAJ. Intranasal interferon as protection against experimental respiratory coronavirus infection in volunteers. Antimicrob Agents Chemother 1983; $24: 713-5$.

22. Barclay WS, Callow KA, Sergeant M, Al-Nakib W. Evaluation of an enzyme-linked immunosorbent assay that measures rhinovirus-specific antibodies in human sera and nasal secretions. J Med Virol 1988; $25: 475-82$.

23. Phillpotts RJ. Clones of MRC-C cells may be superior to the parent line for the culture of 229E-like strains of human respiratory coronavirus. J Virol Methods 1983; 6: 267-9.

24. Holmes MJ, Callow KA, Parry HF. An improved method for recovery of secretory immunoglobulins and lymphocytes from the nasal mucosa. Immunol Methods $1987 ; 48$ : 183-7.

25. Lowry OH, Rosenbrough NJ, Farr AL, Randall RJ. Protein measurement with the folin phenol reagent. J Biol Chem $1951 ; 193: 265-75$.

26. Totman R, Kiff J, Reed SE, Craig JW 1980. Predicting experimental colds in volunteers from different measures of recent life stress. J Psychosom Res $1980 ; 24$ : 155-63.

27. Broadbent DE, Broadbent MHP, Phillpotts RJ, Wallace J. Some further studies on the prediction of experimental colds in volunteers by psychological factors. J Psychosom Res $1984 ; 28: 511-23$.

28. Larson HE, Reed SE, Tyrrell DAJ. Isolation of rhinoviruses and coronaviruses from 38 colds in adults. J Med Virol $1980 ; 5: 221-9$.

29. Tyrrell DAJ. Common colds and related diseases. London: Edward Arnold, 1965: 80-94.

30. Lidwell OM, Williams REO. The epidemiology of the common cold I. J Hyg 1961; 59: 309-19.

31. Cavallaro JJ, Monto AS. Community-wide outbreak of infection with a 229E-like coronavirus in Tecumseh Michigan. J Infect Dis $1970 ; 122: 2729$.

32. Kaye HS, Marsh HB, Dowdle WR. Seroepidemiologic survey of coronavirus strain OC43 related infections in a children's population. Am J Epidemiol 1971 ; 94 : 43-9.

33. Monto AS. Medical reviews: Coronaviruses. Yale J Biol Med 1974; 47 : 234-51. 